九州大学学術情報リポジトリ

Kyushu University Institutional Repository

(Z)-11-hexadecenyl acetate and ( $Z$ ) -13-

octadecenyl acetate improve the attractiveness of the standard sex pheromone of the yellow rice stem borer Scirpophaga incertulas (Lepidoptera: Pyralidae) in northern Vietnam

Ho, Giang Thi Thu

Department of Entomology, Hanoi University of Agriculture

La, Hao V.

Department of Entomology, Hanoi University of Agriculture

Hall, David R.

Natural Resources Institute, University of Greenwich

Le, Thuy D.

Department of Entomology, Hanoi University of Agriculture

他

https://doi.org/10.5109/1434383

出版情報：九州大学大学院農学研究院紀要. 59 (1)，pp.85-89，2014-02-28. Faculty of Agriculture， Kyushu University

バージョン:

権利関係 : 


\title{
$(Z)$-11-hexadecenyl acetate and $(Z)-13$-octadecenyl acetate improve the attractiveness of the standard sex pheromone of the yellow rice stem borer Scirpophaga incertulas (Lepidoptera: Pyralidae) in northern Vietnam
}

\author{
Giang Thi Thu HO ${ }^{1}$, Hao V. LA ${ }^{1}$, David R. HALL ${ }^{2}$, Thuy D. LE ${ }^{1}$, \\ Dinh NGUYEN ${ }^{1}$, Jerry V. CROSS ${ }^{3}$ and Takatoshi UENO ${ }^{4 *}$ \\ Laboratory of Insect Natural Enemies, Institute of Biological Control, Faculty of Agriculture, \\ Kyushu University, Fukuoka 812-8581, Japan \\ (Received October 31, 2013 and accepted November 11, 2013)
}

\begin{abstract}
The attractiveness of a combined lure containing the pheromone components of the yellow rice stem borer Scirpophaga incertulas (Walker) and the rice leaf folder Cnaphalocrosis medinalis (Guenée) to mixed populations of the two species was tested in northern Vietnam. Rubber septa lures containing a 1:3 ratio of $(Z)-9$-hexadecenal and $(Z)-11$-hexadecenal were tested alone and in combination with a 1:1 blend of $(Z)-11$-hexadecenyl acetate and $(Z)-13$ octadecenyl acetate in field experiments in summer rice crops at two locations. Lures containing $(Z)-9$-hexadecenal and $(Z)-11$-hexadecenal were attractive to $S$. incertulas males. The addition of $(Z)$-11-hexadecenyl acetate and $(Z)$-13-octadecenyl acetate significantly improved catches by $120 \%$ on average in five out of six replicated field experiments. No C. medinalis were captured, confirming previous research that the blend of $(Z)$-11-hexadecenyl acetate and $(Z)$-13-octadecenyl acetate is not attractive to this species in northern Vietnam. Ovipositor washings from virgin female $S$. incertulas collected from rice crops in Vietnam were analysed by gas chromatography coupled to mass spectrometry. Hexadecanal, $(Z)-9$-hexadecenal, $(Z)$-11-hexadecenal, $(Z)-9$-octadecenal, and $(Z)-11-$ hexadecen-1-ol were detected in relative amounts of 18:34:100:20:54 with $(Z)-11$-hexadecenal estimated to be present at up to $5 \mathrm{ng} /$ female. Traces of $(Z)-11$-hexadecenyl acetate were also present, but $(Z)-13-$ octadecenyl acetate was not detected. Add one or two sentence(s) to give short conclusion and/or interpretation of the results.
\end{abstract}

Key words: IPM, pheromone traps, rice leaf folder, rice paddies, rice pest control

\section{INTRODUCTION}

In a review of the pests and diseases of rice in Vietnam from 1975 onwards, Van Dinh and Doanh (2010) reported 17 key pests of rice. The most important in terms of crop areas damaged were the brown plant hopper Nilaparvata lugens (Stål), the vector of the ragged stunt and grassed stunt viruses, the rice leaf folder Cnaphalocrosis medinalis (Guenée), and the yellow rice stem borer Scirpophaga incertulas (Walker). Among four stem borer species in the Red River Delta, $S$. incertulas, Chilo suppressalis (Walker), Chilotraea auricilia (Dudgeon) and Sesamia inferens (Walker), S. incertulas was the dominant species, accounting for over $90 \%$ of all stem borer populations (Ho et al., 2013). However, during 2010 and 2011, the incidence of $S$. incertulas at Haiphong Province, a coastal area of Northern Vietnam, was very low (Ho et al., 2013). In northern Vietnam where two rice crops are grown per annum, $S$. incertulas has six generations per year, two on the first crop and four on the second. C. medinalis

\footnotetext{
Department of Entomology, Hanoi University of Agriculture, Vietnam

Natural Resources Institute, University of Greenwich, Chatham Maritime, Kent ME4, UK

East Malling Research, New Road, East Malling, Kent, ME19 6BJ UK

${ }^{4}$ Laboratory of Insect Natural Enemies, Institute of Biological Control, Faculty of Agriculture, Kyushu University, Fukuoka 812-8581, Japan

* Corresponding author (E-mail: ueno@grt.kyushu-u.ac.jp)
}

has eight overlapping generations per year, seven generations being on rice with one generation on wild grasses.

There are two main rice production deltas in Vietnam, i.e., the Red River Delta and the Mekong River Delta, damage caused by $S$. incertulas being greatest in the former. Large areas of rice are mono-cropped in the deltas. In the Red River Delta the rice fields are sub-divided into numerous small contiguous plots (typically 20-50 plots per ha) each managed by a different farmer. In The Mekong River Delta plots are typically 1-10 ha. In both deltas farmers mainly act independently, and, as a result, the application of control measures is generally uncoordinated, resulting in comparatively poor control of these important pests.

Currently, S. incertulas and C. medinalis are controlled with insecticides, one to two spray applications being made on average per crop against each pest, and a wide range of insecticides is used. Sprays to small plots are typically applied with hand lances using knapsack sprayers by individual farmers. The standard of insecticide control is variable and often poor, allowing high populations of the pest in localities to act as a source of infestation for adjacent areas where the pest has previously been well controlled. Better area-wide control tactics for the pests would be beneficial.

The female sex pheromone of $S$. incertulas was originally identified from populations from The Philippines as a 1:3 blend of $(Z)-9$ hexadecenal and $(Z)-11$-hexadecenal (Cork et al., 1985). Cork et al. (1985) also found (Z)-11hexadecen-1-ol and hexadecanal to be produced by females but the former compound reduced catches of 
males and the latter had no apparent effect on attraction of conspecific male moths. Subsequently Tatsuki et al. (1985) identified (Z)-9-octadecenal in ovipositor washings from female $S$. incertulas in addition to the four compounds identified by Cork et al. (1985). In field tests, addition of (Z)-9-octadecenal seemed to increase catches of male moths but the numbers and replicates were too low for statistical analysis, and the increase was mainly due to the catch in one out of three replicates. The field tests also showed that addition of $(Z)-11$-hexadecenol decreased catches. Jiawei et al. (1987) reported the sex pheromone glands of female $S$. incertulas to contain hexadecenal, (Z)-9-hexadecenal and (Z)-11hexadecenal in a 19:27:54 ratio. Traps baited with this blend attracted significant numbers of male moths relative to unbaited controls. These authors could not detect $(Z)-9$-octadecenal. Subsequently, the 1:3 blend of (Z)-9-hexadecenal and $(Z)-11$-hexadecenal has been used as the standard for monitoring $S$. incertulas (Cork et al., 1996; 1998) as addition of (Z)-9-octadecenal did not improve catches in India, though addition of this minor component has not been investigated in northern Vietnam. Standard rubber septum dispensers loaded with $1 \mathrm{mg}$ of the blend are used commercially for population monitoring in many rice production areas though as far as we are aware pheromone traps are not used for monitoring populations of these pests in northern Vietnam. The $S$. incertulas sex pheromone has also been successfully exploited for control by mating disruption in India (Cork and Basu, 1996; Cork et al., 1996, 1998). However, the mating disruption approach used comparatively large amounts of pheromone (10-40 g/ha/season) and is thus comparatively costly. More recently, mass trapping using a lattice of 20 sleeve traps per ha with high dose lures (5-10 mg/lure) has been found to be effective (Cork and Krishnaiah, 2000).

C. medinalis is a migratory species in Asia. The female sex pheromone was originally identified from populations of Indian origin as $(Z)-11$-hexadecenyl acetate and $(Z)-13-$ octadecenyl acetate at a ratio $1: 10$, respectively (Rao et al., 1995). More recently, Kawazu et al. (2000) examined the pheromone from Japanese populations and found $(Z)-11$-octadecenal, $(Z)-13$-octadecenal, (Z)-11-octadecen-1-ol and (Z)-13-octadecen-1-ol in a 11:100:24:36 ratio in ovipositor extracts from virgin females. Subsequently, Kawazu et al. (2005) showed that the Indian blend was not attractive to $C$. medinalis populations in northern Vietam, southern China or Bohol, an island in the southern Philippines. This indicated geographic variation in the sex pheromone composition of this species or presence of several morphologically similar species with different sex pheromone blends.

The aim of this work was to develop more effective pheromone lures for $S$. incertulas and $C$. medinalis for use in northern Vietnam and to determine whether a combined lure for the two species could be developed. Field experiments were carried out in 2011 to investigate the attractiveness of lures containing the standard pheromone components of both $S$. incertulas and $C$. medinalis combined, in comparison with those contain- ing the components of $S$. incertulas only. The results of these experiments are reported here together with the results of chemical analyses of ovipositor washings from virgin female $S$. incertulas collected in northern Vietnam.

\section{MATERIALS AND METHODS}

\section{Field tests}

Experiments were conducted during 2011 autumn rice crops in two 30 ha rice fields, one near Hanoi, the center of the Red River Delta $\left(21^{\circ} 00^{\prime} \mathrm{N}, 105^{\circ} 56{ }^{\prime} \mathrm{E}\right)$ and one near Haiphong, the coastal area (2046'N, $\left.106^{\circ} 42^{\prime} \mathrm{E}\right)$. Damage due to $S$. incertulas was present at high levels in these areas. Experiments were repeated with re-randomisation against the fourth, fifth and six the generations.

Lures were white natural rubber septa (International Pheromone Systems Ltd., Wirral, UK) impregnated with the pheromone components and an equal weight of 2,6-di-tert-butyl-4-methylphenol (BHT) as antioxidant. Virgin female moths used as baits were obtained from a laboratory culture and were 1-2 d old. They were held in muslin cages in the traps.

Traps were each made from one open-sided 1.25liter clear plastic drinks bottle (30 cm tall, $9 \mathrm{~cm}$ diameter). There were three wide openings in the side of each bottle ( $8 \mathrm{~cm}$ tall by $6 \mathrm{~cm}$ wide) and these were equi-spaced round the circumference at mid-height to allow moths to enter. Water + detergent was provided in the base up to a height of $c .1 \mathrm{~cm}$ below the bottom edge of the side holes for drowning moths entering the trap. The lure or the cage with the virgin female were suspended in the trap on a wire and were held approximately $15 \mathrm{~cm}$ above the water. Each trap was hung from the bottle neck with a long nylon string for adjustable height from a bamboo cane, $170 \mathrm{~cm}$ in length and $1.5-2 \mathrm{~cm}$ in diameter and inserted into the ground at $75^{\circ}$ to the horizontal.

For the experiments started in August and September during the fourth and fifth generations, respectively, two treatments were included: A (Standard lure) (Z)-9hexadecenal $(250 \mu \mathrm{g})+(Z)-11$-hexadecenal $(750 \mu \mathrm{g})$; B (Combined lure) (Z)-9-hexadecenal (250 $\mu \mathrm{g})+$ (Z)-11-hexadecenal (750 $\mu \mathrm{g})+(Z)-11$-hexadecenyl acetate $(100 \mu \mathrm{g})+(Z)-13$-octadecenyl acetate $(1,000$ $\mu \mathrm{g})$.

For the experiments started in November during the sixth generation a third treatment was included: $\mathrm{C}$ virgin female held in a muslin cage.

Randomized complete block experimental designs with 5 replicates were used with different randomizations for each experiment. The distance between traps was $30 \mathrm{~m}$. The height of the lure was maintained at $20 \mathrm{~cm}$ higher than the height of the rice canopy. Data collection was done on the morning of each day, the number of males trapped in each trap being recorded and removed from the trap. Total trap catch data were subjected to analysis of variance after square root transformation to stabilize variances using GenStat version 13. Means were compared using a simple LSD test $(\mathrm{P}=0.05)$. 


\section{Analyses of $\boldsymbol{S}$. incertulas ovipositor washings}

Approximately 300 pupae were collected from the Red River Delta, Vietnam, and shipped by courier to the Natural Resources Institute, UK. There they were maintained on reversed $12 \mathrm{~h}: 12 \mathrm{~h} \mathrm{~L}:$ D cycle with temperature $25^{\circ} \mathrm{C}: 20^{\circ} \mathrm{C}$. Ovipositor washings were made in hexane and 9 collections of approximately 10 virgin female adults each were made on the night of emergence or the first night after. Initial washings were made at $2 \mathrm{hr}, 4 \mathrm{hr}$, $6 \mathrm{hr}$ and $8 \mathrm{hr}$ into the dark phase. Most pheromone was obtained at $4 \mathrm{hr}$ and the remaining 5 collections were made after $4 \mathrm{hr}$.

Analyses by gas chromatography (GC) with flame ionization detection (FID) were done on a HP6850 instrument (Agilent, Manchester, UK) with a fused silica capillary column $(30 \mathrm{~m} \times 0.32 \mathrm{~mm}$ i.d. $)$ coated with polar DBWax (Agilent; $0.25 \mu$ film thickness). Carrier gas was helium $(2.4 \mathrm{ml} / \mathrm{min})$, injection splitless $\left(200^{\circ} \mathrm{C}\right)$ and detection by FID $\left(250^{\circ} \mathrm{C}\right)$. The oven temperature was held at $50^{\circ} \mathrm{C}$ for $2 \mathrm{~min}$ and then programmed at $10^{\circ} \mathrm{C} / \mathrm{min}$ to $250^{\circ} \mathrm{C}$. Data were captured and processed with EZChrom Elite (Agilent).
Analyses by GC linked to mass spectrometry (MS) were carried out on a CP-3800 GC coupled directly to a Saturn 2200 MS (Varian, now Agilent) using a fused silica capillary column $(30 \mathrm{~m} \times 0.25 \mathrm{~mm}$ i.d. $)$ coated with polar DBWax (Agilent; $0.25 \mu$ film thickness). Carrier gas was helium $(1 \mathrm{ml} / \mathrm{min})$ and injection splitless $\left(200^{\circ} \mathrm{C}\right)$. The oven temperature was programmed from $40^{\circ} \mathrm{C}$ for 2 min then at $10^{\circ} \mathrm{C} / \mathrm{min}$ to $250^{\circ} \mathrm{C}$.

Compounds were identified by comparison of their GC retention times and mass spectra with those of authentic synthetic standards (Cork et al., 1985).

\section{RESULTS}

\section{Field tests}

The analyses of variance of square root-transformed total trap catch data showed highly significant treatment effects $($ Fprob $<0.003)$ in five of the six trapping experiments, traps baited with the Combined Lure (B) catching significantly more $(P<0.05)$ male $S$. incertulas than those baited with the Standard Lure (A) (Tables 1-3). In the remaining experiment started in August in

Table 1. Average numbers of adult male $S$. incertulas trapped in the experiments started during the fourth generation flight period in Hanoi and Haiphong in August 2011

\begin{tabular}{lcc}
\hline \multirow{2}{*}{ Treatment } & \multicolumn{2}{c}{ Mean catch/trap/night $( \pm \mathrm{SE})^{\mathrm{a}}$} \\
\cline { 2 - 3 } & Hanoi (27 Aug - 9 Oct) & Haiphong (16-30 Aug) \\
\hline A Standard Lure & $0.24 \pm 0.02 \mathrm{~b}$ & $0.61 \pm 0.05 \mathrm{a}$ \\
B Combined Lure & $0.55 \pm 0.03 \mathrm{a}$ & $0.47 \pm 0.05 \mathrm{a}$ \\
\hline
\end{tabular}

${ }^{a}$ Means followed by the same letter are not significantly different $(P>0.05)$ by LSD test after analysis of variance on square root-transformed data.

Table 2. Average numbers of adult male $S$. incertulas trapped in the experiments started during the fifth generation flight period in Hanoi and Haiphong in September 2011

\begin{tabular}{lcc}
\hline \multirow{2}{*}{ Treatment } & \multicolumn{2}{c}{ Mean catch/trap/night $( \pm \mathrm{SE})^{\mathrm{a}}$} \\
\cline { 2 - 3 } & Hanoi $(25 \mathrm{Sep}-30 \mathrm{Oct})$ & Haiphong $(23 \mathrm{Sep}-18 \mathrm{Oct})$ \\
\hline A Standard Lure & $0.24 \pm 0.02 \mathrm{~b}$ & $0.61 \pm 0.05 \mathrm{a}$ \\
B Combined Lure & $0.55 \pm 0.03 \mathrm{a}$ & $0.47 \pm 0.05 \mathrm{a}$ \\
\hline
\end{tabular}

${ }^{a}$ Means followed by the same letter are not significantly different $(P>0.05)$ by LSD test after analysis of variance on square root-transformed data.

Table 3. Average numbers of adult male $S$. incertulas trapped in the experiments started during the sixth generation flight in Hanoi and Haiphong in November 2011

\begin{tabular}{lcc}
\hline \multirow{2}{*}{ Treatment } & \multicolumn{2}{c}{ Mean catch/trap/night $( \pm \mathrm{SE})^{\mathrm{a}}$} \\
\cline { 2 - 3 } A Standard Lure & Hanoi $(6 \mathrm{Nov}-6 \mathrm{Dec})$ & Haiphong $(6-27 \mathrm{Nov})$ \\
\hline B Combined Lure & $1.08 \pm 0.15 \mathrm{~b}$ & $2.98 \pm 0.23 \mathrm{~b}$ \\
C. 1 virgin female & $2.49 \pm 0.23 \mathrm{a}$ & $6.98 \pm 0.86 \mathrm{a}$ \\
\hline
\end{tabular}

${ }^{a}$ Means followed by the same letter are not significantly different $(P>0.05)$ by LSD test after analysis of variance on square root-transformed data 
Haiphong, treatment effects were not statistically significant $($ Fprob $=0.120)$ (Table 1$)$.

In the experiments carried out during the sixth generation, traps baited with a virgin female $S$. incertulas moth caught significantly fewer males $(P<0.05)$ than those baited with either of the synthetic lures (Table 3). Small numbers of $S$. incertulas males were captured in the virgin female baited traps, numbers being much smaller than in the synthetic lure baited traps (Table 3 ). No $C$. medinalis were captured in any of the experiments.

\section{Analyses of $\boldsymbol{S}$. incertulas ovipositor washings}

In analyses of ovipositor washing from virgin female S. incertulas by GC-FID and GC-MS, the presence of five potential pheromone components was confirmed by comparison of GC retention times and mass spectra with those of synthetic standards: hexadecanal, $(Z)-9$ hexadecenal, (Z)-11-hexadecenal, (Z)-9-octadecenal and $(Z)-11$-hexadecen-1-ol (Figure 1). Amounts of (Z)-11-hexadecenal were estimated to be up to $5 \mathrm{ng} /$ female with most material found in ovipositor washings made $4 \mathrm{hr}$ into the dark period. Relative amounts of the five compounds in six samples made at this time (mean $\pm \mathrm{SE})$ were $18( \pm 1.6): 34( \pm 2.5): 100: 20( \pm 2.1): 54$ $( \pm 7.4)$.

The washings contained large amounts of fatty material (Figure 1) and only approximately 0.2 female equivalents could be injected at a time. Under these conditions, $(Z)-11$-octadecenal and $(Z)-13$-octadecenal were not detected. However, in subsequent re-examinations of GC-MS analyses, traces of $(Z)-11$-hexadecenyl acetate $(<<1 \%$ of the amount of $(Z)-11$-hexadecenal) were detected by single ion scanning at $m / z 61,81$ and 222 at the corresponding retention time. No octadecenyl acetate could be detected.

\section{DISCUSSION}

In five out of the six experiments reported here a substantive (overall mean $=120 \%$ ) increase in male $S$. incertulas catches occurred by addition of $(Z)-11$-hexadecenyl acetate and (Z)-13 octadecenyl acetate to $S$. incertulas lures containing the standard Philippine blend of $(Z)-9$ hexadecenal and $(Z)-11$-hexadecenal at a ratio of $1: 3$. The use of acetate components for attracting $S$. incertulas has not been explored previously and captures of this species in traps bated with the $C$. medinalis acetate components alone does not occur as far as we are aware, though we did not test this in these experiments. Our finding was a chance discovery resulting from an attempt to develop a combined lure for both $S$. incertulas and $C$. medinalis. It was interesting that when we examined the results of the GC-MS analysis of the ovipositor washings we found traces of $(Z)-11$-hexadecenyl acetate to be present, though we could find no $(Z)$-13-octadecenyl acetate. Taken together, these results suggest that $(Z)-11$-hexadecenyl acetate may be a minor component of the $S$. incertulas sex pheromone.

In our previous experience in northern Vietnam (Ho, unpublished), catches of $S$. incertulas males in traps baited with the standard Philippine sex pheromone blend have been low, with only a few moths per night caught even when populations in the field were very high, as indicated by catches in UV light traps in the vicinity which comprised many times more, sometimes hundreds of moths per night. Possible reasons for low catches in the sex pheromone traps include poor trap design and/ or omission of minor components. Possible minor components of the $S$. incertulas sex pheromone have been identified in several previous studies. None of these previous studies detected or investigated inclusion of (Z)-11-hexadecenyl acetate and/or (Z)-13-octadecenyl

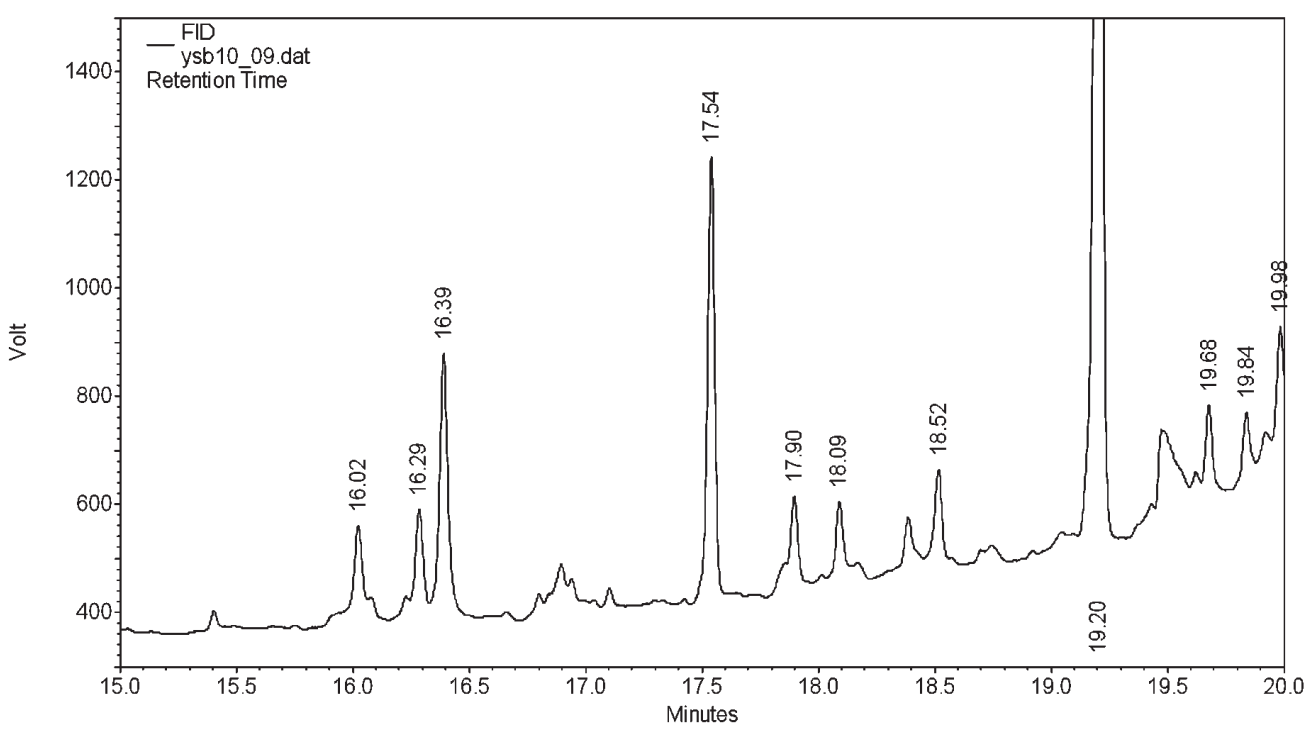

Fig. 1. Analysis of ovipositor washings from female Scirpophaga incertulas by GC-FID on a polar column (hexadecanal at $16.02 \mathrm{~min}$; $(Z)-9$-hexadecenal at $16.29 \mathrm{~min} ;(Z)-11$-hexadecenal at $16.39 \mathrm{~min}$; (Z)-9-octadecenal at $18.09 \mathrm{~min}$; $(Z)-11$-hexadecen-1-ol at $18.52 \mathrm{~min}$; $(Z)$-11-hexadecenyl acetate elutes at $17.80 \mathrm{~min}$; other peaks are tricosane (17.54 min) or fatty acid (19.20 min) impurities). 
acetate for $S$. incertulas, alone or in combination with other components. Our results confirm the findings of Kazawu et al. (2005) that ( $Z$ )-11-hexadecenyl acetate and $(Z)-13$-octadecenyl acetate, the principle pheromone components of $C$. medinalis populations in India (Rao et al., 1995), are unattractive to populations of this species in northern Vietnam.

Future work will investigate the effect of addition of the $(Z)-11$-hexadecenyl acetate and $(Z)-13$-octadecenyl acetate separately at different concentrations to the standard 1:3 blend of $(Z)-9$-hexadecenal and $(Z)-11-$ hexadecenal on attraction of $S$. incertulas. Combination of the Japanese $C$. medinalis blend of (Z)-11octadecenal, $(Z)$-13-octadecenal, $(Z)$-11-octadecen-1-ol and $(Z)$ - 13-octadecen-1-ol, (Kawazu et al., 2000) with the $S$. incertulas blend for attraction of both species would also be interesting to investigate as a combined lure would be useful for mass trapping both species, perhaps requiring only a single treatment application.

\section{ACKNOWLEDGEMENT}

We thank Mr. Hoang Van Dat, Mr. Le Van Chien and Ms. Nguyen T. Nga for their assistance in the field work. This study was supported in part by a Grand-in-Aid from the Vietnam National Foundation for Science and Technology Development (NAFOSTED) (No. 106.11.183.09) and also by a Grant-in-Aid for Scientific Research (B), Japan No 24405028.

\section{REFERENCES}

Cork, A. and S. K. Basu 1996 Control of the yellow stem borer, Scirpophaga incertulas (Walker) (Lepidoptera: Pyralidae) by mating disruption with a PVC resin formulation of the sex pheromone of Chilo suppressalis, in India. Bull. Entomol. Res., 86: $1-9$

Cork, A., P. S. Beevor, D. R. Hall, B. F. Nesbitt, G. S. Arida, and O. Mochida 1985 Components of the female sex pheromone of the yellow stem borer, Scirpophaga incertulas. Entomol. Exp. Appl., 37: 149-153

Cork, A., K. De Souza, K. Krishnaiah, D. V. S. S. R. Kumar, A. Ashok Reddy, and E. Casagrande 1996 Control of yellow stem borer, Scirpophaga incertulas (Walker) (Lepidoptera: Pyralidae) by mating disruption on rice in India: Effect of unnatural pheromone blends and application time on efficacy. Bull. Entomol.
Res., 86: 515-524

Cork, A., K. De Souza, K. Krishnaiah, A. S. Ashok Reddy, and S. Zainullabuddin 1998 Season-long control of yellow stem borer, Scirpophaga incertulas (Lepidoptera: Pyralidae) by mating disruption with the natural ratio of pheromone components. Bull. Entomol. Res., 88: 109-116

Cork, A. and K. Krishnaiah, K. 2000 Pheromones for control of yellow stem borer, Scirpophaga incertulas (Walker) (Lepidoptera: Pyralidae) in India. Proceedings of XXI International Congress of Entomology, Iguassu, Brazil. p. 980

Dinh, N. V. and B. S. Doanh 2010 Remarkable change on the pest composition of rice in 30 years (1976-2005) in Vietnam. In proceeding of the $3^{\text {rd }}$ National Plant Protection (with English summary). Hochiminh City. 16-17/8/2010. pp. 237-245

Ho, G. T. T., C. V. Le, T. H. Nguyen, T. UENO, and D. V. Nguyen 2013 Incidence of Yellow Rice Stem Borer Scirpophaga incertulas Walker in Haiphong, Vietnam and Control Efficacy of Egg Mass Removal and Insecticides. J. Fac. Agric., Kyushu Univ., 58: 301-306

Jiawei, D., D. Xiao, X. Shaofu, T. Xianhan, Z. Taiping, Z. Yuxin, and W. Meizhen 1987 Studies on sex pheromone of yellow rice borer, Scirpophaga incertulas (Walker), Pyralidae, Lepidoptera. Scientia Sinica B, 30: 967-973

Kazawu, K., J. Hasegawa, H. Honda, Y. Ishikawa, S. Wakamura, H. Sugie, H. Kamiwada, T. Kamimuro, Y. Yoshiyasu, and S. Tatsuki 2000 Geographical variation in female sex pheromones of the rice leaffolder moth Cnaphalocrosis medinalis: identification of pheromone components in Japan. Entomol. Exp. Appl. 96: 103-109

Kazawu, K., Y. Suzuki, Y. Yoshiyasu, E. B. Castillon, H. P. T. Vuong, F-K. Huang, T. Adito, T. Fukumoto, and S. Tatsuki 2005 Attraction of Cnaphalocrosis medinalis (Lepidoptera: Crambidae) males in South East Asia to female pheromone traps: Field tests in southernmost China, northern Vietnam and southern Philippines with .three synthetic pheromone blends regarding geographic variations. Appl. Entomol. Zool., 43 483-488

Rao, A. G., D. D. R. Reddy, K. Krishnaiah, P. S. Beevor, A. Cork, and D. R. Hall 1995 Identification and field optimisation of the female sex pheromone of the rice leaffolder, Cnaphalocrocis medinalis in India. Entomol. Exp. Appl., 74: 195-200

Tatsuki, S., H. Sugie, K. Usui, J. Fukami, M. H. Sumartaputra, and A. N. Kuswadi 1985 Identification of possible sex pheromone of the yellow stem borer moth, Scirpophaga incertulas (Walker) (Lepidoptera: Pyralidae). Appl. Entomol. Zool., 20 357-359 